Review

\title{
Thymoquinone, as an anticancer molecule: from basic research to clinical investigation
}

\author{
Md. Asaduzzaman Khan ${ }^{1,2}$, Mousumi Tania ${ }^{3}$, Shangyi Fu ${ }^{4}$ and Junjiang Fu ${ }^{1}$ \\ ${ }^{1}$ Key Laboratory of Epigenetics and Oncology, The Research Center for Preclinical Medicine, Southwest Medical University, \\ Luzhou, Sichuan, China \\ ${ }^{2}$ Faculty of Applied Sciences, Ton Duc Thang University, Ho Chi Minh City, Vietnam \\ ${ }^{3}$ Division of Computer Aided Drug Design, The Red-Green Computing Centre, Dhaka, Bangladesh \\ ${ }^{4}$ The Honors College, University of Houston, Houston, Texas, United States \\ Correspondence to: Junjiang Fu, email: fujunjiang@swmu.edu.cn, fujunjiang@hotmail.com \\ Md. Asaduzzaman Khan, email: asadkhan@swmu.edu.cn, asadkhanbmj@yahoo.com \\ Keywords: Nigella sativa, thymoquinone, anticancer, mouse model, clinical studies
}

Received: March 13, 2017 Accepted: April 05, $2017 \quad$ Published: April 18, 2017

Copyright: Khan et al. This is an open-access article distributed under the terms of the Creative Commons Attribution License 3.0 (CC BY 3.0), which permits unrestricted use, distribution, and reproduction in any medium, provided the original author and source are credited.

\section{ABSTRACT}

\begin{abstract}
Thymoquinone is an anticancer phytochemical commonly found in black cumin. In this review, we discuss the potential of thymoquinone as anticancer molecule, its mechanism of action and future usage in clinical applications. Thymoquinone exhibits anticancer activity via numerous mechanisms of action, specifically by showing selective antioxidant and oxidant activity, interfering with DNA structure, affecting carcinogenic signaling molecules/pathways and immunomodulation. In vitro activity of thymoquinone has been further implicated in animal models of cancer; however, no clinical application has been proven yet. This is the optimum time to focus on clinical trials for developing thymoquinone as a future drug in cancer therapeutics.
\end{abstract}

\section{INTRODUCTION}

Every year, millions of people are diagnosed with cancer, which is the second leading cause of death worldwide after myocardial infarction. Fortunately, the number of cancer survivors is increasing, mainly due to advances in early detection and new treatment strategies. It has been reported that more than 15.5 million Americans with a history of cancer are alive by January 2016 [1]. However, in many regions in the world, including East Asian countries, cancer is still the major public health problem with increasing incidence and mortality rate [2]. As for now, chemotherapy is one of the most common treatment option in cancer therapy, which continues to increase the amount of anticancer drugs used for treatment; even so, most people use a combination of treatments, such as surgery with chemotherapy and radiation therapy.

Unfortunately, chemotherapeutic agents create many adverse side effects. Currently, there is a trend in searching for anticancer chemicals in natural sources, as natural products are usually thought to be less toxic and produce minimal side effects. Drugs from natural sources have been used traditionally for thousands of years in various parts of the world. Scientists have targeted many traditional or folk medicines in parallel of modern medicine to identify and extract active ingredients for the drug development. Thymoquinone (2-methyl-5-isopropyl-1,4-benzoquinone) (Figure 1) is a phytochemical compound found in black cumin (Nigella sativa) with a long history of medicinal use $[3,4]$. The black cumin seeds have a notable history in traditional medicine practices mainly in South and Southeastern Asia, Arab, Africa and Mediterranean regions. In ancient Egypt, Greece and Turkey, black cumin seeds were often used to treat a number of diseases and ailments [3-6]. Both seeds and oil from Nigella sativa plants are used in medicinal purposes, and they are known for their anticancer, antidiabetic, antihypertensive, antimicrobial, analgesic, immunomodulatory, anti-inflammatory, spasmolytic, hepato-protective, renal-protective, gastroprotective, bronchodilative and antioxidant activities [4-6]. Its versatile healing abilities have given the black cumin seed its name 'Panacea' (in Latin, meaning 'cure all'), and 'Habbah Sawda' or 'Habbat el Baraka' (in Arabic, translated as 'Seeds of blessing)'. It is also known as 'Kalo jeera' (in Bangladesh), 'Kalonji' (in India) and 'hēi zhǒng căo' (in China). Black cumin seeds and oil are also known as 'Prophetic medicine', as the Islamic prophet has deemed its high potential as medicine [4-7]. 
In recent years, many scientific studies have revealed the anticancer potential of thymoquinone, however, there is no clinical application yet. In this review, we discuss the potential of thymoquinone as anticancer molecule, and its mechanism of action and future usage in clinical applications.

\section{Thymoquinone in modern anticancer research: efficacy and mechanisms of action}

Thymoquinone was identified and quantified in black cumin seed oils by Ghosheh et al., [8] with other compounds named dithymoquinone, thymohydroquinone and thymol. Over a decade ago, some scientists became interested in anticancer activities of thymoquinone. Since then, a number of studies have been carried out to evaluate the anticancer or chemopreventive role and mechanism of action of thymoquinone in different cancer cell lines and animal models of different cancer types (Table 1, Figure 2).

\section{Antioxidant activity of thymoquinone}

Initial experimental studies suggested that the antioxidant activity of thymoquinone is responsible for its chemopreventive activities; however, some other studies reported thymoquinone induce apoptosis in cancer cells by exerting oxidative damage [9-13]. An interesting study reported that thymoquinone is actually a potent apoptosis inducer in cancer cells, but it exerts antiapoptotic effect through attenuating oxidative stress in other types of cell injury [14]. Another hypothesis states that thymoquinone acts as an antioxidant at lower concentrations and a prooxidant at higher concentrations [15]. The antioxidant, antiproliferative and proapoptotic activity of thymoquinone was further explained by Cecarini et al. [16], demonstrating that thymoquinone induces selective proteasome inhibition, which could be implicated in the induction of apoptosis in cancer cells. Further study by Torres et al. [17] revealed that thymoquinone down-regulates glycoprotein mucin 4 (MUC4) expression through the proteasomal pathway and induces apoptosis in pancreatic cancer cells by activating c-Jun $\mathrm{NH}(2)$-terminal kinase (JNK) and p38 mitogenactivated protein kinase (MAPK) pathways. Usually, MUC4 is aberrantly expressed in pancreatic cancer, and contributes to the regulation of cellular differentiation, proliferation, metastasis and chemoresistance.

\section{Thymoquinone interferes with DNA structure and synthesis}

Thymoquinone also acts via interference with DNA structure. It targets cellular copper, which is present in the chromatin and is closely associated with DNA base guanine, and causes oxidative breakage to DNA and consequent cancer cell death [15]. Thymoquinone can possibly act as a G-quadruplex DNA stabilizer and subsequently contribute to the inhibition of telomerase enzyme and cancer's proliferation [18]. It can induce DNA damage and telomere attrition by inhibiting telomerase and cell death in glioblastoma cells with minimal effects to normal cells [19]. It can also affect DNA synthesis in cancer cells. In an earlier study, thymoquinone was found to inhibit DNA synthesis, proliferation, and viability of cancerous cells, such as LNCaP, C4-B, DU145, and PC-3, but not noncancerous BPH-1 prostate epithelial cells [20].

\section{Thymoquinone targets carcinogenic signaling pathways}

A number of carcinogenic signaling pathways or signaling molecules have been reported as thymoquinone's target. Down-regulation of androgen receptor (AR) and

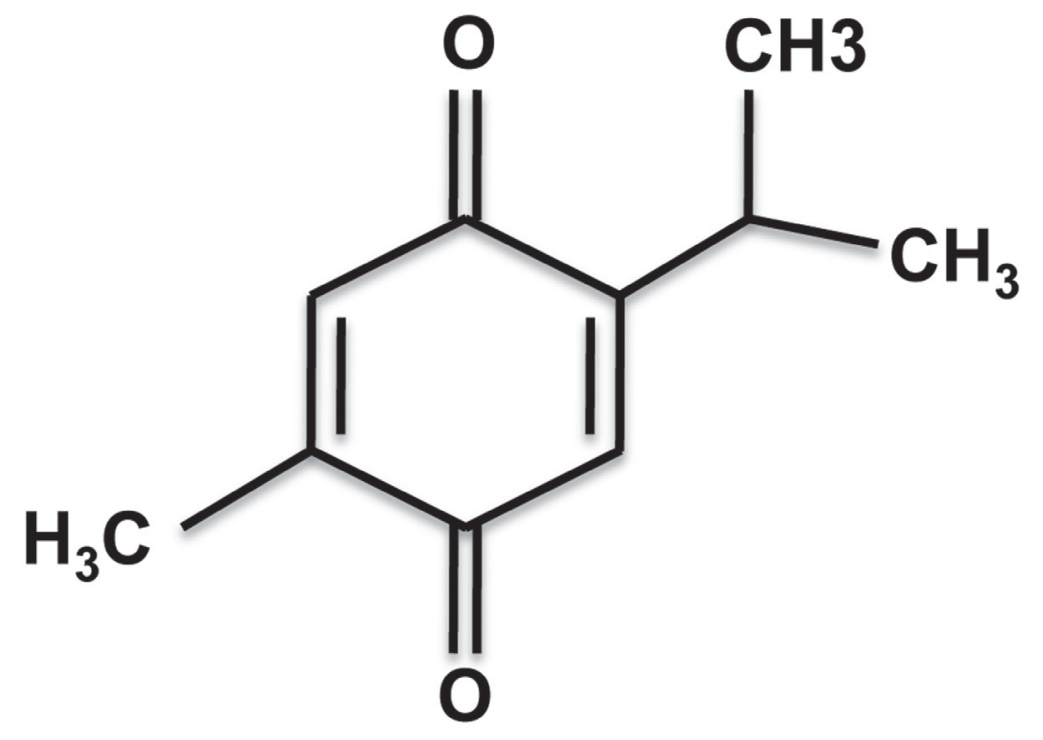

Figure 1: The molecular structure of thymoquinone (Chemical name: 2-Isopropyl-5-methylbenzo-1,4-quinone). 
Table 1: Thymoquinone's action against different cancers

\begin{tabular}{|c|c|c|c|c|}
\hline Cancer types & Cell lines & Animal model & Mechanism of action of thymoquinone & Ref. \\
\hline $\begin{array}{l}\text { Acute } \\
\text { lymphoblastic } \\
\text { leukemia }\end{array}$ & CEM-ss & & $\begin{array}{l}\text { Generates ROS and HSP70, down-regulates Bcl-2, } \\
\text { up-regulates Bax, activates caspase } 3,8 \text { for inducing } \\
\text { apoptosis }\end{array}$ & {$[30]$} \\
\hline Bladder cancer & $\mathrm{T} 24$ & & $\begin{array}{l}\text { Attenuates mTOR activity, and inhibits PI3K/Akt } \\
\text { signaling }\end{array}$ & {$[52,53]$} \\
\hline \multirow[t]{4}{*}{ Breast cancer } & $\begin{array}{l}\text { MDA- } \\
\text { MB-468, } \\
\text { T47D }\end{array}$ & & $\begin{array}{l}\text { Interferes with PI3K/Akt signaling and promotes } \mathrm{G}(1) \\
\text { arrest }\end{array}$ & {$[27]$} \\
\hline & $\mathrm{MCF}-7$ & & Up-regulates p53 & {$[31]$} \\
\hline & BT549 & & Down-regulates TWIST1 and EMT & {$[51]$} \\
\hline & & Mouse & 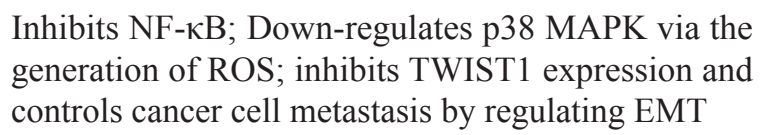 & {$[51,58,65]$} \\
\hline Cervical cancer & $\mathrm{HeLa}$ & & Inhibits serine/threonine kinase Plk1 & {$[21]$} \\
\hline \multirow[t]{4}{*}{ Colon cancer } & HCT116 & & $\begin{array}{l}\text { Induces apoptosis by up-regulating Bax and inhibiting } \\
\text { Bcl-2, as well as activation of caspases }-9,-7 \text { and } \\
-3 \text { and induction of PARP cleavage; blocks STAT3 } \\
\text { signaling via inhibition of JAK2- and Src-mediated } \\
\text { phosphorylation of EGFR tyrosine kinase. }\end{array}$ & {$[25]$} \\
\hline & $\begin{array}{l}\text { CPT-11-R } \\
\text { LoVo }\end{array}$ & & Induces caspase-independent autophagy & {$[43]$} \\
\hline & & Rat & Exert oxidative stress & {$[55]$} \\
\hline & & Mouse & $\begin{array}{l}\text { Delays the growth of tumor, reduces tumor cell } \\
\text { invasion and also increases apoptosis }\end{array}$ & {$[56]$} \\
\hline Colorectal cancer & $\begin{array}{l}\text { HCT116w, } \\
\text { DLD-1, } \\
\text { HT29 }\end{array}$ & & $\begin{array}{l}\text { Binds to oncogene PAK1, changes its conformation } \\
\text { and scaffold function, and interferes with RAF/MEK/ } \\
\text { ERK1/2 pathway and controls cancer cell growth }\end{array}$ & {$[47]$} \\
\hline $\begin{array}{l}\text { Cholangio- } \\
\text { carcinoma }\end{array}$ & $\begin{array}{l}\text { TFK-1, } \\
\text { HuCCT1 }\end{array}$ & & $\begin{array}{l}\text { Down-regulates } \mathrm{PI} 3 \mathrm{~K} / \mathrm{Akt} \text { and } \mathrm{NF}-\kappa \mathrm{B} \text {, and their } \\
\text { regulated gene products, such as } \mathrm{p}-\mathrm{AKT}, \mathrm{p} 65 \text {, XIAP, } \\
\mathrm{Bcl}-2, \mathrm{COX}-2 \text { and VEGF }\end{array}$ & {$[46]$} \\
\hline $\begin{array}{l}\text { Familial } \\
\text { adenomatous } \\
\text { polyposis }\end{array}$ & & Mouse & $\begin{array}{l}\text { Interferes with polyp progression through induction of } \\
\text { tumor-cell specific apoptosis and by modulating Wnt } \\
\text { signaling through the activation of GSK-3 } \beta\end{array}$ & {$[63]$} \\
\hline \multirow[t]{2}{*}{ Gastric cancer } & $\begin{array}{l}\text { HGC27, } \\
\text { BGC } 823 \\
\text { SGC7901 }\end{array}$ & & $\begin{array}{l}\text { Inhibits STAT3 phosphorylation, associated with } \\
\text { reduction in JAK } 2 \text { and c-Src activity, as well as Bcl- } \\
2 \text {, cyclin D, survivin, and VEGF }\end{array}$ & {$[24]$} \\
\hline & & Mouse & Down-regulates STAT3 & {$[24]$} \\
\hline \multirow[t]{2}{*}{ Glioblastoma } & $\begin{array}{l}\text { M059K, } \\
\text { M059J }\end{array}$ & & $\begin{array}{l}\text { Induces DNA damage, telomere attrition by inhibiting } \\
\text { telomerase and cell death }\end{array}$ & [19] \\
\hline & $\begin{array}{l}\text { U-87, CCF- } \\
\text { STTG1 }\end{array}$ & & $\begin{array}{l}\text { Down-regulates FAK, associated with a reduction of } \\
\text { ERK phosphorylation as well MMP-2 and MMP-9 } \\
\text { secretion, and consequently inhibits cell migration } \\
\text { and invasion }\end{array}$ & {$[48]$} \\
\hline Hepatic carcinoma & HepG2 & & $\begin{array}{l}\text { Stimulates expression of pro-apoptotic Bcl-xS and } \\
\text { TRAIL death receptors, and inhibits expression of the } \\
\text { anti-apoptotic gene Bcl-2, as well as inhibits NF- } \kappa B \\
\text { and IL-8 and stimulates apoptosis }\end{array}$ & {$[45]$} \\
\hline
\end{tabular}




$\begin{array}{ll}\text { Lung cancer } & \text { A549 } \\ \text { Multiple myeloma } & \text { U266, } \\ & \text { RPMI8226 }\end{array}$

Murine Leukemia WEHI-3 Mouse

Myeloid leukemia KBM-5 such as, glutathione peroxidase, glutathione-stransferase and catalase; regulates $\mathrm{G} 1 / \mathrm{S}$ phase cell cycle transition

Reduces ERK1/2 phosphorylation and controls [50] proliferation and migration

Inhibits IL-6-inducible STAT3 phosphorylation, [23, 38, 93] which is correlated with the inhibition of c-Src and JAK2 activation. Also inhibits the expression of STAT3-regulated gene products, D1, Bcl-2, Bcl-xL, survivin, Mcl-1 and VEGF, which ultimately induces apoptosis

Increases early apoptosis through the up-regulation of Bcl-2, and down-regulation of Bax.

Suppresses TNF- $\alpha$-induced NF- $\kappa B$ activation, and consequently inhibits the activation of $\mathrm{I}-\kappa \mathrm{B}$ alpha kinase, I- $\kappa \mathrm{B}$ alpha phosphorylation, I- $\kappa \mathrm{B}$ alpha degradation, p65 phosphorylation, p65 nuclear translocation, and the NF- $\mathrm{KB}$-dependent reporter gene expression; Also down-regulates the expression of $\mathrm{NF}-\kappa \mathrm{B}$-regulated antiapoptotic gene products like IAP1, IAP2, XIAP Bcl-2, Bcl-xL, and surviving; proliferative gene products like cyclin D1, cyclooxygenase-2, and c-Myc, and angiogenic gene products MMP-9 and VEGF

Down-regulates proliferation activator p38 MAPK

Generates ROS to induce oxidative damage and $[11,70]$ apoptosis

Antioxidant activity controls cancer cell growth

Inhibits DNA synthesis and proliferation

Down-regulates MUC4 expression through the proteasomal pathway and induces apoptosis by the activation of JNK) and p38 MAPK pathways

Down-regulates MMP-9, XIAP

\begin{tabular}{lll}
$\begin{array}{l}\text { Squamous } \\
\text { carcinoma }\end{array}$ & cell Mouse & $\begin{array}{l}\text { Inhibits cell proliferation and induces apoptosis by [62] } \\
\text { inhibiting Akt and JNK phosphorylations }\end{array}$ \\
\hline
\end{tabular}

\begin{tabular}{lll}
$\begin{array}{l}\text { Squamous } \\
\text { carcinoma }\end{array}$ & Mouse & $\begin{array}{l}\text { Inhibits cell proliferation and induces apo } \\
\text { inhibiting Akt and JNK phosphorylations }\end{array}$ \\
\hline
\end{tabular}

cell proliferation regulator E2F-1 was indicated as the mechanism behind thymoquinone's action in prostate cancer [20]. Thymoquinone and its synthetic derivative poloxin was found to inhibit the serine/threonine kinase Polo-like kinase 1 (Plk1) (usually over-expressed in many types of cancers) by interfering with its intracellular localization [21]. Another important target of thymoquinone is the signal transducer and activator of transcription 3 (STAT3) pathway. In a study, thymoquinone was found to inhibit both constitutive and interleukin-6 (IL-6)-inducible STAT3 phosphorylation, which is correlated with the inhibition of c-Src and JAK2 (Janus kinase) activation. Also, the expression of STAT3regulated gene products, such as cyclin D1, Bcl-2, Bcl-xL, survivin, Mcl-1 and vascular endothelial growth factor
(VEGF), was inhibited by thymoquinone, which ultimately increased apoptosis and killed cancer cells or inhibited their growth [22]. Suppression of STAT3 phosphorylation by thymoquinone was also found to be associated with decrease of F-actin polymerization and reduction of proliferation of human multiple myeloma cells [23]. Thymoquinone's inhibition of STAT3 phosphorylation, associated with reduction in JAK2 and c-Src activity, as well as Bcl-2, cyclin D, survivin, and VEGF was also reported in gastric cancer cells [24]. In human colon cancer cells (HCT116), thymoquinone induced apoptosis, which was associated with the up-regulation of Bax and the inhibition of Bcl-2 as well as the activation of caspases $-9,-7$ and -3 and the induction of the cleavage of poly-(ADP-ribose) polymerase (PARP) [25]. 
In molecular level, it was found that thymoquinone exerts effects by blocking STAT3 signaling via the inhibition of JAK2- and Src-mediated phosphorylation of EGFR tyrosine kinase [25]. In oral cancer cells (T28), thymoquinone showed anticancer activity via the down-regulation of proliferation activator p38 MAPK [26]. In breast cancer cell lines (MDA-MB-468 and T47D), thymoquinone interfered with PI3K/Akt signaling and promoted G(1) arrest and induced apoptosis [27]. Thymoquinone inhibited p53-mutated acute lymphoblastic leukemia (ALL) cells via the activation of a p73-dependent mitochondrial and cell cycle checkpoint signaling pathway; this pathway subsequently targets the anti-apoptotic and epigenetic integrator UHRF1, which is essential for cell cycle progression [28]. Furthermore, it was found that downregulation of cyclic nucleotide phosphodiesterase PDE1A is the key event of p73 and UHRF1 deregulation in thymoquinone-induced ALL cell apoptosis [29]. In ALL cell line CEM-ss, thymoquinone treatment generated reactive oxygen species (ROS) and HSP70, downregulated Bcl-2, up-regulated Bax, and activated caspase 3 and caspase 8 for inducing apoptosis [30]. A recent study confirms that thymoquinone can induce apoptosis in MCF-7 breast cancer cells via the up-regulation of p53 expression [31]. Thymoquinone significantly increased the expression of miR-34a via p53, and down-regulated Rac1 expression, followed by actin depolymerisation and disruption of the actin cytoskeleton [32]. This damage in the actin cytoskeleton leads to a significant reduction in the lamellipodia and filopodia formation on cell surfaces, thus retarding cell migration [32]. In hepatic carcinoma, thymoquinone induced cell cycle arrest and apoptosis by repressing the Notch signaling pathway [33]. A detail on the thymoquinone action in different signaling pathways involved in cancer has been reviewed by Rahmani et al. [34].

\section{Immunomodulatory activities of thymoquinone}

The immunomodulatory activity of thymoquinone is another important mechanism of its anticancer activity. Evidence revealed that thymoquinone suppresses tumor necrosis factor (TNF- $\alpha$ )-induced NF-kappa B (NF- $\kappa \mathrm{B})$ activation, and consequently inhibits the activation of I kappa $\mathrm{B}$ alpha $(\mathrm{I}-\kappa \mathrm{B} \alpha)$ kinase, I- $\kappa \mathrm{B} \alpha$ phosphorylation, $\mathrm{I}-\kappa \mathrm{B} \alpha$ degradation, p65 phosphorylation, p65 nuclear translocation, and $\mathrm{NF}-\kappa \mathrm{B}$-dependent reporter gene expression [35]. It also down-regulated the expression of NF- $\kappa \mathrm{B}$-regulated antiapoptotic gene products, like IAP1, IAP2, XIAP Bcl-2, Bcl-xL; surviving proliferative gene products, like cyclin D1, cyclooxygenase-2 (COX-2), and c-Myc; and angiogenic gene products like matrix metalloproteinase-9 (MMP-9) and VEGF [35]. Thymoquinone was found to suppress NF- $\kappa \mathrm{B}$ signaling and IL-8 expression in childhood malignant brain tumor medulloblastoma, and it induced both extrinsic and intrinsic pathways of apoptosis [36]. It also inhibited monocyte chemo-attractant protein-1 (MCP-1), TNF- $\alpha$, interleukin (IL)- $1 \beta$ and COX-2, ultimately reducing the $\mathrm{NF}-\kappa \mathrm{B}$ activation in pancreatic ductal adenocarcinoma cells, indicating its role as an inhibitor of proinflammatory pathways [37]. In multiple myeloma cells, thymoquinone was found to inhibit CXCL12-induced chemotaxis and

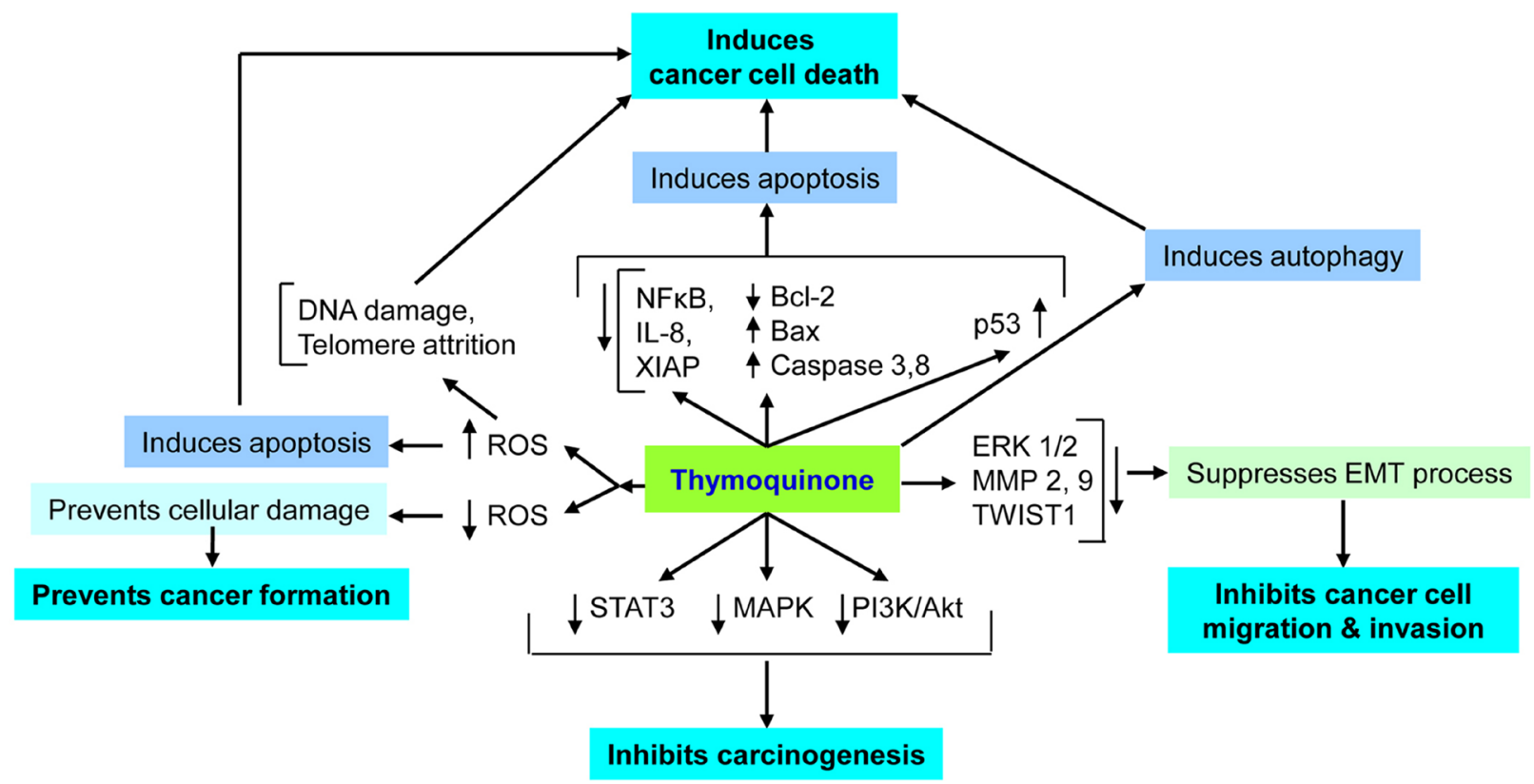

Figure 2: Important mechanisms of thymoquinone's anticancer action. Thymoquionone induces apoptosis in cancer cells via generating reactive oxygen species (ROS), DNA damage, telomeric attrition, immunomodulation, regulating signaling pathways and autophagy induction. Thymoquinone also regulates epitheilial to mesenchymal transition (EMT) and inhibits cancer metastasis. In noncancer cells, thymoquione shows anti-oxidant activities and chemopreventive activity. 
increase their susceptibility to Fas-mediated apoptosis [38]. Thymoquinone is also involved in conditioning $\mathrm{T}$ cells in vitro for adoptive T-cell therapy against cancer, reported by Salem et al. [39], as it enhances the survival and activity of antigen-specific CD8-positive $\mathrm{T}$ cell. Activated B-cell lymphoma (ABC) is a subtype of diffuse large B-cell lymphoma (DLBCL), which has the worst survival rate after upfront chemotherapy, and is characterized by constitutively activated NF- $\kappa \mathrm{B}$ [40]. Thymoquinone induced the release of ROS in $\mathrm{ABC}$ cell lines, which, in turn, inhibited NF- $\kappa \mathrm{B}$ activity by dephosphorylating $\mathrm{I}-\kappa \mathrm{B} \alpha$ and reducing the translocation of p65 subunit of $\mathrm{NF}-\kappa \mathrm{B}$ in the nuclear compartment of cells [40]. In addition to apoptosis induction, thymoquinone also plays a role in inducing autophagy in glioblastoma cells [41]. Autophagy induction was also reported in head and neck squamous cell carcinoma (HNSCC) as a result of thymoquinone treatment [42]. Thymoquinone induced caspase-independent autophagic cell death by increasing the mitochondrial outer membrane permeability and activation of JNK and p38 in CPT11-R LoVo colon cancer cells [43]. Without affecting the tubulin levels in normal human fibroblast, thymoquinone induces degradation of $\alpha$ and $\beta$ tubulin proteins in human astrocytoma U87 cells and in T lymphoblastic leukaemia Jurkat cells, and thus exerts anticancer activity [44]. Thymoquinone treatment in hepatic carcinoma cells (HepG2) stimulated mRNA expression of proapoptotic Bcl-xS and TRAIL death receptors, inhibited the expression of the anti-apoptotic gene Bcl-2, inhibited NF- $\kappa \mathrm{B}$ and IL-8, and stimulated apoptosis [45]. In cholangiocarcinoma cell lines (TFK-1 and HuCCT1), thymoquinone showed anticancer activity by downregulating $\mathrm{PI} 3 \mathrm{~K} / \mathrm{Akt}$ and $\mathrm{NF}-\kappa \mathrm{B}$ and other regulated gene products, such as p-AKT, p65, XIAP, Bcl-2, COX-2 and VEGF [46]. Another study revealed that thymoquinone binds to oncogene PAK1, changes its conformation and scaffold function, and interferes with RAF/MEK/ERK1/2 pathway in colorectal cancer [47].

\section{Thymoquinone's effects on cancer cell migration and invasion}

In addition to controling cancer cell proliferation, thymoquinone also reduces cancer metastasis. In human glioblastoma U-87 and CCF-STTG1 cells, thymoquinone treatment was found to influence a drastic downregulation of Focal Adhesion Kinase (FAK), associated with a reduction of ERK phosphorylation and matrix metalloproteinase (MMP-2 and MMP-9) secretion, consequently inhibiting cell migration and invasion [48]. The immunotherapeutic and anti-metastatic role of thymoquinone in controlling and preventing metastatic melanoma has been reported in another study, where the NLRP3 inflammasome was found to be the target of thymoquinone [49]. Thymoquinone inhibited human non- small carcinoma cell lung cancer (A549 cell) proliferation and migration by reducing ERK1/2 phosphorylation [50]. It has been evident that thymoquinone treatment inhibits TWIST1 promoter activity and decreases its expression in breast cancer cell lines; leading to the inhibition of epithelial-mesenchymal transition (EMT) mediated cancer cell migration, invasion and metastasis [51]. Along with interfering with EMT, thymoquinone also attenuated mTOR activity, and inhibited PI3K/Akt signaling in bladder cancer $[52,53]$.

\section{In vivo success of thymoquinone as anticancer molecule}

Over the last decade, a number of studies used thymoquinone against animal cancer models. Similar to in vitro studies, in vivo investigations also revealed the antioxidant activity of thymoquinone in controlling rat hepatic carcinoma by decreasing the expression of antioxidant enzymes, such as glutathione peroxidase, glutathione-s-transferase and catalase [54]. In 1,2-dimethyl-hydrazine (DMH)-induced oxidative stress during the initiation and promotion of colon carcinogenesis in rats, thymoquinone showed chemopreventive activity by reducing oxidative stress [55]. In colorectal cancer model of mice, thymoquinone delayed the growth of tumors, reduced tumor cell invasion and increased apoptosis [56]. In a study by Yi et al. [57], thymoquinone was found effective in inhibiting human umbilical vein endothelial cell migration, invasion, and tube formation, thus preventing tumor angiogenesis in xenograft prostate cancer model in mice. In cellular level, suppressing the activation of Akt was indicated as mode of action [57]. In addition, thymoquionone modulates the immune system of animals, as it inhibited NF- $\kappa B$ expression in breast cancer model of mice and interferes with later stages of mammary tumor progression [58].

In nude mice model of human pancreatic carcinoma, thymoquinone showed anti-neoplastic and anti-metastatic effects by down-regulating MMP-9 and X-linked inhibitor of apoptosis protein (XIAP) [59]. XIAP is actually a caspase inhibitor, which was found to be down-regulated by thymoquinone also in mouse neuroblastoma cells (Neuro-2a) [60]. Degradation of XIAP and inactivation of Akt by thymoquinone has been reported in breast cancer model in vitro and in vivo, where thymoquinone exerts anti-angiogenic and anti-invasive activities [61]. In mouse xenograft model of squamous cell carcinoma, thymoquinone was found to inhibit cell proliferation and induce apoptosis by inhibiting Akt and JNK phosphorylation [62].

In mouse model of familial adenomatous polyposis (FAP), thymoquinone interfered with polyp progression by inducting tumor-cell specific apoptosis and by modulating Wnt signaling through the activation of GSK-3 $\beta$, thus reducing the risk of colorectal cancer [63]. 
In hepatocellular carcinoma model of rat, thymoquinone showed anti-proliferative activity by regulating the G1/S phase cell cycle transition [64]. In breast cancer xenograft model of mice, thymoquinone showed anti-proliferative and pro-apoptotic effects by down-regulating p38 MAPK via the generation of ROS [65]. In triple negative breast cancer, thymoquinone reduced phosphorylation of Akt, decreased expression of XIAP, and enhanced cisplatinand docetaxel-induced cytotoxicity [66]. Thymoquinone combined with paclitaxel showed anti-tumor activity by interplaying with the apoptosis network in triple-negative breast cancer [67]. In xenograft model of gastric cancer mice, thymoquinone showed anticancer activity by downregulating STAT3 pathway [24].

In murine leukemic WEHI-3 cells, thymoquinone promoted natural killer of cell activities and showed highly effective cellular cytotoxicity seen in an increase of early apoptosis, up-regulation of antiapoptotic protein $\mathrm{Bcl} 2$, and down-regulation of apoptotic protein Bax; this result was also implicated in WEHI-3 cell growth in the BALB/c mice [68]. In 7,12-dimethylbenz[a] anthracene (DMBA) induced breast cancer, thymoquinone treatment showed antioxidant potential and reduced MDA, LDH, ALP and AST activities and decreased the expression of Brca1, Brca2 and Id-1, consequently preventing cancer development [69]. Another in vivo study revealed that thymoquinone has anti-osteoclastogenic effect by inhibiting inflammation-induced activation of MAPKs, NF- $\kappa \mathrm{B}$ and ROS generation followed by suppressing the gene expression of c-Fos and NFATc1 in osteoclast precursors [70]. In experimentally induced breast cancer model of mouse, thymoquinone inhibited tumor growth and cancer metastasis [51].

\section{Road to clinical investigation: problems and solutions}

\section{Current clinical trials}

There is not any clinical trial for thymoquinone registered by the U.S government yet (https://clinicaltrials. gov/ct2/results?term=Thymoquinone). However, in an Arabian Phase I trial thymoquinone was found safe and well tolerated in patients upto $10 \mathrm{mg} / \mathrm{kg} / \mathrm{day}$, but at this dosage, there was no significant anticancer activity found [71]. The use of thymoquinone in humans is limited due to its chemical properties and poor membrane penetration capacity. Thymoquinone is chemically hydrophobic, which causes its poor solubility, and thus bioavailability. In addition, high lipophilicity of thymoquinone causes poor formulation characteristics [72]. A number of experimental studies have been conducted to overcome the pharmacokinetic problems of thymoquinone, its adverse effect. Some studies revealed that thymoquinone in combination with other chemotherapeutic drugs can show better anticancer activities, which might be an interesting option in future clinical investigation of thymoquinone.

\section{Pharmacokinetic characteristics of thymoquinone}

Pharmacokinetic studies showed that thymoquinone is rapidly eliminated and slowly absorbed, and hence thymoquinone has less bioavailability. The calculated absolute bioavailability of thymoquinone was reported $\sim 58 \%$ with a lag time of $\sim 23$ min by Alkharfy et al. [73]. Several chemical derivatives have been used to improve the pharmacokinetic behavior of thymoquinone to increase the bioavailability. Thymoquinone4- $\alpha$-linolenoylhydrazone and thymoquinone-4palmitoylhydrazone was found to inhibit cell proliferation dependent on p53 status by activating the cell cycle inhibitor p21 [74]. Also the development of nanoparticles has created a remarkable approach in thymoquinone delivery, which might be very effective in enhancing bioavailabity. Thymoquinone-loaded liposomes (TQ-LP) and thymoquinone loaded in liposomes modified with Triton X-100 (XLP) with diameters of about $100 \mathrm{~nm}$ were found to maintain stability, improve bioavailability and maintain thymoquinone's anticancer activity [72]. Encapsulation of TQ into nanoparticles with $97.5 \%$ efficiency in biodegradable nanoparticulate formulation based on poly (lactide-co-glycolide) (PLGA) and stabilizer polyethylene glycol (PEG)-5000 enhances its antiproliferative, anti-inflammatory, and chemosensitizing effects [75]. Thymoquinone packaged in nanoparticles have been proved more useful to improve bioavailability, which is called 'nanochemoprevention' or 'nanochemotherapy' [76]. A double mesoporous core-shell silica spheres (DMCSSs) loaded with thymoquinone was found more effective in inducing cancer cell apoptosis than free thymoquinone, due to the slow release of the drug from the mesoporous structure [77]. However, studies revealed that the aqueous solubility of thymoquinone is not a major obstacle for the drug formulations, as it possesses considerable water solubility ( $>500 \mu \mathrm{g} / \mathrm{mL}$ ), which may be enough to exert pharmacologic effects after parenteral route administration [78]. Thymoquinoneloaded nanostructured lipid carrier (TQ-NLC) has been developed to improve its bioavailability (elimination halflife $\sim 5$ hours), which can exhibit cytotociity against cancer cell lines by inducing apoptosis and cell cycle arrest $[79,80]$. Bhattacharya et al. [32] developed thymoquinoneencapsulated nanoparticles using biodegradable, hydrophilic polymers, like polyvinylpyrrolidone and polyethyleneglycol to overcome thymoquinone's poor solubility, thermal and light sensitivity, and minimal systemic bioavailability, which can greatly improve the cancer treatment's efficiency. This nanoparticle can induce breast cancer cell killing and reduced migration. Myristic acid-chitosan (MA-chitosan) nanogels were prepared by Dehghani et al. [81] and thymoquinone was loaded into the nanogels for the treatment of human breast adenocarcinoma cell MCF-7. Interestingly, this nanogel was found more effective in anticancer activity than thymoquinone alone. 


\section{Optimum dose of thymoquinone}

Another problem of clinical usage of thymoquinone lies in the safety issue. The LD50 in mice was determined $104.7 \mathrm{mg} / \mathrm{kg}$ after intra-peritoneal injection and $870.9 \mathrm{mg} / \mathrm{kg}$ after oral ingestion of thymoquionone, and in rats, LD50 was found to be $57.5 \mathrm{mg} / \mathrm{kg}$ and $794.3 \mathrm{mg} / \mathrm{kg}$ after intraperitoneal and oral ingestion respectively [82]. However, thymoquinone shows anticancer activity in very small concentrations, approximately $<10 \mathrm{mg} / \mathrm{kg}[51,82]$. Thus, safety issue might not pose a big problem.

\section{Combination of thymoquinone with other chemotherapeutic drugs}

Combination of thymoquinone with other clinically used anticancer drugs may enhance chemotherapeutic potentiality. In fact, thymoquinone has been proved to be very effective in synergistic anticancer activity with available drugs. While 5-fluorouracil is regarded as the chemotherapeutic gold-standard for certain cancers, especially colon cancer, thymoquinone's activity was found closely comparable to 5-fluorouracil in both SW-626 human colon cancer cell killing and intercellular metabolic function interference. Moreover, when used in combination with 5-fluorouracil, thymoquionone augments its apoptotic activity in gastric cancer cells in vitro and in vivo $[83,84]$. A combination of thymoquionone, 5-fluorouracil, and epigallocatechin-3-gallate showed more potent anticancer activity against $\mathrm{FaDu}$ nasopharyngeal carcinoma cell and SK-OV-3 ovarian cancer cell line $[85,86]$. A recent study reports that 5 -fluorouracil and thymoquinone cooperate to repress the expression of procancerous Wnt, $\beta$-catenin, NF- $\mathrm{kB}, \mathrm{COX}-$ 2 , iNOS, VEGF, and TBRAS; up-regulate the expression of anti-tumorigenesis DKK-1, CDNK-1A, TGF- $\beta 1$, TGF$\beta$ RII, Smad4, and GPx; and show chemopreventive effects on colorectal carcinogenesis in rats [87]. Doxorubicin is another chemotherapeutic drug, whose anticancer activity is improved by combining thymoquinone in a cell-line specific manner, specifically in HL-60 and multi-drug resistant MCF-7/TOPO cancer cells [88]. Thymoquinone also induces apoptosis by up-regulating PTEN and inhibiting Akt phosphorylation in doxorubicin-resistant human breast cancer cells [89]. Cisplatin is one of the most active chemotherapeutic agents in lung cancer. Combination of cisplatin and thymoquinone is highly effective in non-small cell lung cancer (NSCLC), small cell lung cancer (SCLC) cell lines and mouse xenograft model; this combination is even able to overcome the cisplatin resistance [90]. In fact, thymoquinone was reported to be more potent than cisplatin in killing human cervical squamous carcinoma cells $\mathrm{SiHa}$ by inducing apoptosis with Bcl-2 down-regulation [91].
Thymoquinone enhanced cisplatin-mediated cytoxicity in ID8-NGL mouse ovarian cancer cells and ovarian cancer model C57BL/6 mice. Thymoquinone treatment actually promoted cisplatin-induced pH2AX (double-strand DNA break marker) expression in cultured cells and in tumors [92]. In multiple myeloma treatment, thymoquinone can enhance the anticancer activity of bortezomib in vitro and in vivo, and can even overcome chemoresistance [93]. Castrate-resistant prostate cancer (CRPC) is a major concern in cancer therapeutic research. The combination of thymoquione and docetaxel has been proved to be effective against CRPC cells in inducing cytotoxicity and apoptosis by modulating PI3K-Akt pathway [94]. Thymoquinone pretreatment following gemcitabine treatment synergistically increased apoptosis and inhibited tumor growth in pancreatic cancer in vitro and in vivo. This combination contributes to suppression of Notch1 and NICD accompanying with up-regulation of PTEN, inactivation of Akt/mTOR/S6 signaling pathways, and the suppression of phosphorylation and nuclear translocation of p65 induced by TNF- $\alpha$. Thymoquinone pretreatment with gemcitabine therapy also down-regulated antiapoptotic Bcl-2, Bcl-xL, and XIAP; it also up-regulated or activated the pro-apoptotic molecules, such as, Caspase-3, Caspase-9, Bax and increased release of cytochrome c [95]. Thymoquinone in combination with mesalazine reduced tumor development and multiplicity in Msh2 (loxP/loxP) Villin-Cre mice by reducing microsatellite instability independent of a functional mismatch repair system [96]. In hormone and drug resistant prostate cancer cells (PC-3 and DU-145), thymoquionone in combination with zoledronic acid showed significant synergistic cytotoxic activity and DNA fragmentation, as well as increased the caspase 3/7 activity in PC-3 cell line [97]. In combination with paclitaxel, thymoquinone was found very effective against triple negative breast cancer, both drugs worked synergistically [67]. Thymoquinone also increased the efficacy of tamoxifen in inducing apoptosis in human breast cancer cells MCF-7 and MDA-MB-231 [98]. Glioblastoma multiforme is one of the most lethal forms of human cancer, and thymoquinone was found to enhance the anticancer activity of temozolomide, which is currently part of the standard treatment for this disease [99]. A recent study showed that thymoquinone can potentiate the chemopreventive effect of vitamin D during the initiation phase of colon cancer in rat model [100]. In addition to chemotherapeutic combination, as an adjuvant, thymoquinone also mediates radiosensitization and cancer chemo-radiotherapy [101]; in combination with single dose of ionizing radiation (2.5 Gy), thymoquinone was found to exert supra-additive cytotoxic effects on MCF7 and T47D breast cancer cells by enhancing apoptosis and cell cycle modulation. Interestingly, our group recently found that thymoquinone can synergistically enhance the potential of another therapeutic agent, miR-34a [102]. 


\section{Future direction}

Considering the multiple molecular mechanism of thymoquinone action, its potency in small concentrations, in vivo success, enhanced bioavailability, success in combination with other drugs, it is time to focus on clinical trials for thymoquinone. Moreover, the basic biochemical or molecular biological investigations should be continued for the better understanding of the molecular mechanisms of thymoquinone. Using the nanomaterial encapsulation of thymoquinone, synthesizing its more effective new chemical derivatives with more potential pharmacokinetic characteristics might be interesting in future drug development and clinical usage. As targeting specific cancer therapeutics is a major focus in present anticancer treatment, specific molecular targets for thymoquinone, like enzymes, receptors, DNA or RNA materials should also be kept under investigation.

\section{CONCLUSIONS}

Thymoquinone is evident as a potent anticancer molecule by regulating numerous molecular mechanisms, and it has the potential to be a good therapeutic small molecule in the prevention and treatment of cancer. Now is the right time to think about clinical trials, specifically Phase I trials. For thymoquinone delivery, it can be administered in a very low dosage encapsulated in a lipophilic biogels or nanoparticles, or be used in combination with other established chemotherapeutic drugs. Meanwhile, laboratory investigations should continue for better understanding of molecular mechanism of thymoquinone action to develop potent analogs with limited side effects and a more convenient drug delivery system, ultimately improving cancer management system.

\section{CONFLICTS OF INTEREST}

The authors declare that there is no conflicts of interest regarding this paper.

\section{FUNDING}

This work was supported by the National Natural Science Foundation of China $(81672887,81172049)$.

\section{REFERENCES}

1. Miller KD, Siegel RL, Lin CC, Mariotto AB, Kramer JL, Rowland JH, Stein KD, Alteri R, Jemal A. Cancer treatment and survivorship statistics, 2016. CA Cancer J Clin. 2016; 66:271-289.

2. Chen W, Zheng R, Baade PD, Zhang S, Zeng H, Bray F, Jemal A, Yu XQ, He J. Cancer statistics in China, 2015. CA Cancer J Clin. 2016; 66:115-132.
3. Padhye S, Banerjee S, Ahmad A, Mohammad R, Sarkar FH. From here to eternity - the secret of Pharaohs: Therapeutic potential of black cumin seeds and beyond. Cancer Ther. 2008; 6:495-510.

4. Khan MA, Chen HC, Tania M, Zhang DZ. Anticancer activities of Nigella sativa (black cumin). Afr J Tradit Complement Altern Med. 2011; 8:226-232.

5. Ahmad A, Husain A, Mujeeb M, Khan SA, Najmi AK, Siddique NA, Damanhouri ZA, Anwar F. A review on therapeutic potential of Nigella sativa: A miracle herb. Asian Pac J Trop Biomed. 2013; 3:337-352.

6. Salih B, Sipahi T, Dönmez EO. Ancient nigella seeds from Boyali Höyük in north-central Turkey. J Ethnopharmacol. 2009; 124:416-420.

7. Aggarwal BB, Kunnumakkara AB, Harikumar KB, Tharakan ST, Sung B, Anand P. Potential of spice-derived phytochemicals for cancer prevention. Planta Med. 2008; 74:1560-1569.

8. Ghosheh OA, Houdi AA, Crooks PA. High performance liquid chromatographic analysis of the pharmacologically active quinones and related compounds in the oil of the black seed (Nigella sativa L.). J Pharm Biomed Anal. 1999; 19:757-762.

9. Richards LR, Jones P, Hughes J, Benghuzzi H, Tucci M. The physiological effect of conventional treatment with epigallocatechin-3-gallate, thymoquinone, and tannic acid on the LNCaP cell line. Biomed Sci Instrum. 2006; 42:357-362.

10. Richards LR, Jones P, Benghuzzi H, Tucci M. A comparison of the morphological changes associated with conventional and sustained treatment with pigallocatechin3gallate, thymoquinone, and tannic acid on lncap cells. Biomed Sci Instrum. 2008; 44:465-470.

11. Roepke M1, Diestel A, Bajbouj K, Walluscheck D, Schonfeld P, Roessner A, Schneider-Stock R, GaliMuhtasib H. Lack of p53 augments thymoquinone-induced apoptosis and caspase activation in human osteosarcoma cells. Cancer Biol Ther. 2007; 6:160-169.

12. Hussain AR, Ahmed M, Ahmed S, Manogaran P, Platanias LC, Alvi SN, Al-Kuraya KS, Uddin S. Thymoquinone suppresses growth and induces apoptosis via generation of reactive oxygen species in primary effusion lymphoma. Free Radic Biol Med. 2011; 50:978-987.

13. Dergarabetian EM, Ghattass KI, El-Sitt SB, Al-Mismar RM, El-Baba CO, Itani WS, Melhem NM, El-Hajj HA, Bazarbachi AA, Schneider-Stock R, Gali-Muhtasib HU. Thymoquinone induces apoptosis in malignant T-cells via generation of ROS. Front Biosci (Elite Ed). 2013; 5:706-719.

14. Abd El-Ghany RM, Sharaf NM, Kassem LA, Mahran LG, Heikal OA. Thymoquinone triggers anti-apoptotic signaling targeting death ligand and apoptotic regulators in a model of hepatic ischemia reperfusion injury. Drug Discov Ther. 2009; 3:296-306.

15. Zubair H, Khan HY, Sohail A, Azim S, Ullah MF, Ahmad A, Sarkar FH, Hadi SM. Redox cycling of endogenous copper 
by thymoquinone leads to ROS-mediated DNA breakage and consequent cell death: putative anticancer mechanism of antioxidants. Cell Death Dis. 2013; 4:e660.

16. Cecarini V, Quassinti L, Di Blasio A, Bonfili L, Bramucci M, Lupidi G, Cuccioloni M, Mozzicafreddo M, Angeletti M, Eleuteri AM. Effects of thymoquinone on isolated and cellular proteasomes. FEBS J. 2010; 277:2128-2141.

17. Torres MP, Ponnusamy MP, Chakraborty S, Smith LM, Das S, Arafat HA, Batra SK. Effects of thymoquinone in the expression of mucin 4 in pancreatic cancer cells: implications for the development of novel cancer therapies. Mol Cancer Ther. 2010; 9:1419-1431.

18. Salem AA, El Haty IA, Abdou IM, Mu Y. Interaction of human telomeric G-quadruplex DNA with thymoquinone: a possible mechanism for thymoquinone anticancer effect. Biochim Biophys Acta. 2015; 1850:329-342.

19. Gurung RL, Lim SN, Khaw AK, Soon JF, Shenoy K, Mohamed Ali S, Jayapal M, Sethu S, Baskar R, Hande MP. Thymoquinone induces telomere shortening, DNA damage and apoptosis in human glioblastoma cells. PLoS One. 2010; 5:e12124.

20. Kaseb AO, Chinnakannu K, Chen D, Sivanandam A, Tejwani S, Menon M, Dou QP, Reddy GP. Androgen receptor and E2F-1 targeted thymoquinone therapy for hormone-refractory prostate cancer. Cancer Res. 2007; 67:7782-7788.

21. Reindl W, Yuan J, Krämer A, Strebhardt K, Berg T. Inhibition of polo-like kinase 1 by blocking polo-box domain-dependent protein-protein interactions. Chem Biol. 2008; 15:459-466.

22. Li F, Rajendran P, Sethi G. Thymoquinone inhibits proliferation, induces apoptosis and chemosensitizes human multiple myeloma cells through suppression of signal transducer and activator of transcription 3 activation pathway. Br J Pharmacol. 2010; 161:541-554.

23. Badr G, Mohany M, Abu-Tarboush F. Thymoquinone decreases F-actin polymerization and the proliferation of human multiple myeloma cells by suppressing STAT3 phosphorylation and Bcl2/Bcl-XL expression. Lipids Health Dis. 2011; 10:236.

24. Zhu WQ, Wang J, Guo XF, Liu Z, Dong WG. Thymoquinone inhibits proliferation in gastric cancer via the STAT3 pathway in vivo and in vitro. World J Gastroenterol. 2016; 22:4149-4159.

25. Kundu J, Choi BY, Jeong CH, Kundu JK, Chun KS. Thymoquinone induces apoptosis in human colon cancer HCT116 cells through inactivation of STAT3 by blocking JAK2- and Src mediated phosphorylation of EGF receptor tyrosine kinase. Oncol Rep. 2014; 32:821-828.

26. Abdelfadil E, Cheng YH, Bau DT, Ting WJ, Chen LM, Hsu HH, Lin YM, Chen RJ, Tsai FJ, Tsai CH, Huang CY. Thymoquinone induces apoptosis in oral cancer cells through p38ß inhibition. Am J Chin Med. 2013; 41:683-696.

27. Rajput S, Kumar BN, Dey KK, Pal I, Parekh A, Mandal M. Molecular targeting of Akt by thymoquinone promotes
G(1) arrest through translation inhibition of cyclin D1 and induces apoptosis in breast cancer cells. Life Sci. 2013; 93:783-790.

28. Alhosin M, Abusnina A, Achour M, Sharif T, Muller C, Peluso J, Chataigneau T, Lugnier C, Schini-Kerth VB, Bronner C, Fuhrmann G. Induction of apoptosis by thymoquinone in lymphoblastic leukemia Jurkat cells is mediated by a p73dependent pathway which targets the epigenetic integrator UHRF1. Biochem Pharmacol. 2010; 79:1251-1260.

29. Abusnina A, Alhosin M, Keravis T, Muller CD, Fuhrmann G, Bronner C, Lugnier C. Down-regulation of cyclic nucleotide phosphodiesterase PDE1A is the key event of p73 and UHRF1 deregulation in thymoquinoneinduced acute lymphoblastic leukemia cell apoptosis. Cell Signal. 2011; 23:152-160.

30. Salim LZ, Mohan S, Othman R, Abdelwahab SI, Kamalidehghan B, Sheikh BY, Ibrahim MY. Thymoquinone induces mitochondria-mediated apoptosis in acute lymphoblastic leukaemia in vitro. Molecules. 2013; 18:11219-11240.

31. Dastjerdi MN, Mehdiabady EM, Iranpour FG, Bahramian H. Effect of Thymoquinone on P53 Gene Expression and Consequence Apoptosis in Breast Cancer Cell Line. Int J Prev Med. 2016; 7:66.

32. Bhattacharya S, Ahir M, Patra P, Mukherjee S, Ghosh S, Mazumdar M, Chattopadhyay S, Das T, Chattopadhyay D, Adhikary A. PEGylated-thymoquinone-nanoparticle mediated retardation of breast cancer cell migration by deregulation of cytoskeletal actin polymerization through miR-34a. Biomaterials. 2015; 51:91-107.

33. Ke X, Zhao Y, Lu X, Wang Z, Liu Y, Ren M, Lu G, Zhang D, Sun Z, Xu Z, Song JH, Cheng Y, Meltzer SJ, et al. TQ inhibits hepatocellular carcinoma growth in vitro and in vivo via repression of Notch signaling. Oncotarget. 2015; 6:32610-32621. doi: 10.18632/oncotarget.5362.

34. Rahmani AH, Alzohairy MA, Khan MA, Aly SM. Therapeutic Implications of Black Seed and Its Constituent Thymoquinone in the Prevention of Cancer through Inactivation and Activation of Molecular Pathways. Evid Based Complement Alternat Med. 2014; 2014:724658.

35. Sethi G, Ahn KS, Aggarwal BB. Targeting nuclear factorkappa B activation pathway by thymoquinone: role in suppression of antiapoptotic gene products and enhancement of apoptosis. Mol Cancer Res. 2008; 6:1059-1070.

36. Ashour AE, Ahmed AF, Kumar A, Zoheir KM, AboulSoud MA, Ahmad SF, Attia SM, Abd-Allah AR, Cheryan VT, Rishi AK. Thymoquinone inhibits growth of human medulloblastoma cells by inducing oxidative stress and caspase-dependent apoptosis while suppressing NF- $\mathrm{kB}$ signaling and IL-8 expression. Mol Cell Biochem. 2016; 416:141-155.

37. Chehl N, Chipitsyna G, Gong Q, Yeo CJ, Arafat HA. Antiinflammatory effects of the Nigella sativa seed extract, thymoquinone, in pancreatic cancer cells. HPB (Oxford). 2009; 11:373-381. 
38. Badr G, Lefevre EA, Mohany M. Thymoquinone inhibits the CXCL12-induced chemotaxis of multiple myeloma cells and increases their susceptibility to Fas-mediated apoptosis. PLoS One. 2011; 6:e23741.

39. Salem ML, Alenzi FQ, Attia WY. Thymoquinone, the active ingredient of Nigella sativa seeds, enhances survival and activity of antigen-specific CD8-positive $\mathrm{T}$ cells in vitro. Br J Biomed Sci. 2011; 68:131-137.

40. Hussain AR, Uddin S, Ahmed M, Al-Dayel F, Bavi PP, Al-Kuraya KS. Phosphorylated I $\kappa \mathrm{B} \alpha$ predicts poor prognosis in activated B-cell lymphoma and its inhibition with thymoquinone induces apoptosis via ROS release. PLoS One. 2013; 8:e60540.

41. Racoma IO, Meisen WH, Wang QE, Kaur B, Wani AA. Thymoquinone inhibits autophagy and induces cathepsinmediated, caspase-independent cell death in glioblastoma cells. PLoS One. 2013; 8:e72882.

42. Chu SC, Hsieh YS, Yu CC, Lai YY, Chen PN. Thymoquinone induces cell death in human squamous carcinoma cells via caspase activation-dependent apoptosis and LC3-II activation-dependent autophagy. PLoS One. 2014; 9:e101579.

43. Chen MC, Lee NH, Hsu HH, Ho TJ, Tu CC, Hsieh DJ, Lin YM, Chen LM, Kuo WW, Huang CY. Thymoquinone induces caspase-independent, autophagic cell death in CPT-11-resistant lovo colon cancer via mitochondrial dysfunction and activation of JNK and p38. J Agric Food Chem. 2015; 63:1540-1546.

44. Alhosin M, Ibrahim A, Boukhari A, Sharif T, Gies JP, Auger C, Schini-Kerth VB. Anti-neoplastic agent thymoquinone induces degradation of $\alpha$ and $\beta$ tubulin proteins in human cancer cells without affecting their level in normal human fibroblasts. Invest New Drugs. 2012; 30:1813-1819.

45. Ashour AE, Abd-Allah AR, Korashy HM, Attia SM, Alzahrani AZ, Saquib Q, Bakheet SA, Abdel-Hamied HE, Jamal S, Rishi AK. Thymoquinone suppression of the human hepatocellular carcinoma cell growth involves inhibition of IL-8 expression, elevated levels of TRAIL receptors, oxidative stress and apoptosis. Mol Cell Biochem. 2014; 389:85-98.

46. Xu D, Ma Y, Zhao B, Li S, Zhang Y, Pan S, Wu Y, Wang J, Wang D, Pan H, Liu L, Jiang H. Thymoquinone induces $\mathrm{G} 2 / \mathrm{M}$ arrest, inactivates PI3K/Akt and nuclear factor- $\kappa \mathrm{B}$ pathways in human cholangiocarcinomas both in vitro and in vivo. Oncol Rep. 2014; 31:2063-2070.

47. El-Baba C, Mahadevan V, Fahlbusch FB, Mohan SS, Rau TT, Gali-Muhtasib H, Schneider-Stock R. Thymoquinone-induced conformational changes of PAK1 interrupt prosurvival MEK-ERK signaling in colorectal cancer. Mol Cancer. 2014; 13:201.

48. Kolli-Bouhafs K, Boukhari A, Abusnina A, Velot E, Gies JP, Lugnier $\mathrm{C}$, Rondé $\mathrm{P}$. Thymoquinone reduces migration and invasion of human glioblastoma cells associated with FAK, MMP-2 and MMP-9 down-regulation. Invest New Drugs. 2012; 30:2121-2131.
49. Ahmad I, Muneer KM, Tamimi IA, Chang ME, Ata MO, Yusuf N. Thymoquinone suppresses metastasis of melanoma cells by inhibition of NLRP3 inflammasome. Toxicol Appl Pharmacol. 2013; 270:70-76.

50. Yang J, Kuang XR, Lv PT, Yan XX. Thymoquinone inhibits proliferation and invasion of human nonsmall-cell lung cancer cells via ERK pathway. Tumour Biol. 2015; 36:259-269.

51. Khan MA, Tania M, Wei C, Mei Z, Fu S, Cheng J, $\mathrm{Xu}$ J, Fu J. Thymoquinone inhibits cancer metastasis by downregulating TWIST1 expression to reduce epithelial to mesenchymal transition. Oncotarget. 2015; 6:19580-19591. doi: 10.18632/oncotarget.3973.

52. Iskender B, Izgi K, Hizar E, Jauch J, Arslanhan A, Yuksek EH, Canatan H. Inhibition of epithelial-mesenchymal transition in bladder cancer cells via modulation of mTOR signalling. Tumour Biol. 2016; 37:8281-8291.

53. Iskender B, Izgi K, Canatan H. Novel anti-cancer agent myrtucommulone-A and thymoquinone abrogate epithelialmesenchymal transition in cancer cells mainly through the inhibition of PI3K/AKT signalling axis. Mol Cell Biochem. 2016; 416:71-84.

54. Sayed-Ahmed MM, Aleisa AM, Al-Rejaie SS, AlYahya AA, Al-Shabanah OA, Hafez MM, Nagi MN. Thymoquinone attenuates diethylnitrosamine induction of hepatic carcinogenesis through antioxidant signaling. Oxid Med Cell Longev. 2010; 3:254-261.

55. Jrah-Harzallah H, Ben-Hadj-Khalifa S, Almawi WY, Maaloul A, Houas Z, Mahjoub T. Effect of thymoquinone on 1,2-dimethyl-hydrazine-induced oxidative stress during initiation and promotion of colon carcinogenesis. Eur $\mathrm{J}$ Cancer. 2013; 49:1127-1135.

56. Gali-Muhtasib H, Ocker M, Kuester D, Krueger S, ElHajj Z, Diestel A, Evert M, El-Najjar N, Peters B, Jurjus A, Roessner A, Schneider-Stock R. Thymoquinone reduces mouse colon tumor cell invasion and inhibits tumor growth in murine colon cancer models. J Cell Mol Med. 2008; 12:330-342.

57. Yi T, Cho SG, Yi Z, Pang X, Rodriguez M, Wang Y, Sethi G, Aggarwal BB, Liu M. Thymoquinone inhibits tumor angiogenesis and tumor growth through suppressing AKT and extracellular signal-regulated kinase signaling pathways. Mol Cancer Ther. 2008; 7:1789-1796.

58. Connelly L, Barham W, Onishko HM, Sherrill T, Chodosh LA, Blackwell TS, Yull FE. Inhibition of NFkappa B activity in mammary epithelium increases tumor latency and decreases tumor burden. Oncogene. 2011; 30:1402-1412.

59. Wang YM. [Inhibitory effects of thymoquinone on human pancreatic carcinoma orthotopically implanted in nude mice]. [Article in Chinese]. Zhonghua Yi Xue Za Zhi. 2011; 91:3111-3114.

60. Rajput S, Kumar BN, Sarkar S, Das S, Azab B, Santhekadur PK, Das SK, Emdad L, Sarkar D, Fisher PB, Mandal M. Anti-cancer effects of thymoquinone in mouse neuroblastoma (Neuro-2a) cells through caspase-3 
activation with down-regulation of XIAP. Toxicol Lett. 2012; 213:151-159.

61. Rajput S, Kumar BN, Sarkar S, Das S, Azab B, Santhekadur PK, Das SK, Emdad L, Sarkar D, Fisher PB, Mandal M. Targeted apoptotic effects of thymoquinone and tamoxifen on XIAP mediated Akt regulation in breast cancer. PLoS One. 2013; 8:e61342.

62. Das S, Dey KK, Dey G, Pal I, Majumder A, MaitiChoudhury S, Kundu SC, Mandal M. Antineoplastic and apoptotic potential of traditional medicines thymoquinone and diosgenin in squamous cell carcinoma. PLoS One. 2012; 7:e46641.

63. Lang $\mathrm{M}$, Borgmann $\mathrm{M}$, Oberhuber $\mathrm{G}$, Evstatiev $\mathrm{R}$, Jimenez K, Dammann KW, Jambrich M, Khare V, Campregher C, Ristl R, Gasche C. Thymoquinone attenuates tumor growth in ApcMin mice by interference with Wnt-signaling. Mol Cancer. 2013; 12:41.

64. Raghunandhakumar S, Paramasivam A, Senthilraja S, Naveenkumar C, Asokkumar S, Binuclara J, Jagan S, Anandakumar P, Devaki T. Thymoquinone inhibits cell proliferation through regulation of $\mathrm{G} 1 / \mathrm{S}$ phase cell cycle transition in N-nitrosodiethylamine-induced experimental rat hepatocellular carcinoma. Toxicol Lett. 2013; 223:60-72.

65. Woo CC, Hsu A, Kumar AP, Sethi G, Tan KH. Thymoquinone inhibits tumor growth and induces apoptosis in a breast cancer xenograft mouse model: the role of $\mathrm{p} 38$ MAPK and ROS. PLoS One. 2013; 8:e75356.

66. Sutton KM, Greenshields AL, Hoskin DW. Thymoquinone, a bioactive component of black caraway seeds, causes G1 phase cell cycle arrest and apoptosis in triple-negative breast cancer cells with mutant p53. Nutr Cancer. 2014; 66:408-418.

67. Şakalar Ç, İzgi K, İskender B, Sezen S, Aksu H, Çakır M, Kurt B, Turan A, Canatan H. The combination of thymoquinone and paclitaxel shows anti-tumor activity through the interplay with apoptosis network in triplenegative breast cancer. Tumour Biol. 2016; 37:4467-4477.

68. Salim LZ, Othman R, Abdulla MA, Al-Jashamy K, Ali HM, Hassandarvish P, Dehghan F, Ibrahim MY, Omer FA, Mohan S. Thymoquinone inhibits murine leukemia WEHI3 cells in vivo and in vitro. PLoS One. 2014; 9:e115340.

69. Linjawi SA, Khalil WK, Hassanane MM, Ahmed ES. Evaluation of the protective effect of Nigella sativa extract and its primary active component thymoquinone against DMBA-induced breast cancer in female rats. Arch Med Sci. 2015; 11:220-229.

70. Thummuri D, Jeengar MK, Shrivastava S, Nemani H, Ramavat RN, Chaudhari P, Naidu VG. Thymoquinone prevents RANKL-induced osteoclastogenesis activation and osteolysis in an in vivo model of inflammation by suppressing NF-KB and MAPK Signalling. Pharmacol Res. 2015; 99:63-73.

71. Al-Amri AA, Bamoasa AO. Phase I safety and clinical activity of thymoquinone in patients with advanced refractory malignant disease. Shiraz E-Med J. 2009; 10:107-111.

72. Odeh F, Ismail SI, Abu-Dahab R, Mahmoud IS, Al Bawab A. Thymoquinone in liposomes: a study of loading efficiency and biological activity towards breast cancer. Drug Deliv. 2012; 19:371-377.

73. Alkharfy KM, Ahmad A, Khan RM, Al-Shagha WM. Pharmacokinetic plasma behaviors of intravenous and oral bioavailability of thymoquinone in a rabbit model. Eur $\mathrm{J}$ Drug Metab Pharmacokinet. 2015; 40:319-323.

74. Wirries A, Breyer S, Quint K, Schobert R, Ocker M. Thymoquinone hydrazone derivatives cause cell cycle arrest in p53-competent colorectal cancer cells. Exp Ther Med. $2010 ; 1: 369-375$.

75. Ravindran J, Nair HB, Sung B, Prasad S, Tekmal RR, Aggarwal BB. Thymoquinone poly (lactide-co-glycolide) nanoparticles exhibit enhanced anti-proliferative, antiinflammatory, and chemosensitization potential. Biochem Pharmacol. 2010; 79:1640-1647.

76. Nair HB, Sung B, Yadav VR, Kannappan R, Chaturvedi MM, Aggarwal BB. Delivery of antiinflammatory nutraceuticals by nanoparticles for the prevention and treatment of cancer. Biochem Pharmacol. 2010; 80:1833-1843.

77. El-Toni AM, Khan A, Ibrahim MA, Labis JP, Badr G, Al-Hoshan M, Yin S, Sato T. Synthesis of double mesoporous core-shell silica spheres with tunable core porosity and their drug release and cancer cell apoptosis properties. J Colloid Interface Sci. 2012; 378:83-92.

78. Salmani JM, Asghar S, Lv H, Zhou J. Aqueous solubility and degradation kinetics of the phytochemical anticancer thymoquinone; probing the effects of solvents, $\mathrm{pH}$ and light. Molecules. 2014; 19:5925-5939.

79. Ng WK, Saiful Yazan L, Yap LH, Wan Nor Hafiza WA, How CW, Abdullah R. Thymoquinone-loaded nanostructured lipid carrier exhibited cytotoxicity towards breast cancer cell lines (MDA-MB-231 and MCF-7) and cervical cancer cell lines (HeLa and SiHa). Biomed Res Int. 2015; 2015:263131.

80. Abdelwahab SI, Sheikh BY, Taha MM, How CW, Abdullah R, Yagoub U, El-Sunousi R, Eid EE. Thymoquinone-loaded nanostructured lipid carriers: preparation, gastroprotection, in vitro toxicity, and pharmacokinetic properties after extravascular administration. Int J Nanomedicine. 2013; 8:2163-2172.

81. Dehghani H, Hashemi M, Entezari M, Mohsenifar A. The comparison of anticancer activity of thymoquinone and nanothymoquinone on human breast adenocarcinoma. Iran J Pharm Res. 2015; 14:539-546.

82. Al-Ali A, Alkhawajah AA, Randhawa MA, Shaikh NA. Oral and intraperitoneal LD50 of thymoquinone, an active principle of Nigella sativa, in mice and rats. J Ayub Med Coll Abbottabad. 2008; 20:25-27.

83. Norwood AA, Tucci M, Benghuzzi H. A comparison of 5-fluorouracil and natural chemotherapeutic agents, EGCG 
and thymoquinone, delivered by sustained drug delivery on colon cancer cells. Biomed Sci Instrum. 2007; 43:272-277.

84. Lei X, Lv X, Liu M, Yang Z, Ji M, Guo X, Dong W. Thymoquinone inhibits growth and augments 5-fluorouracilinduced apoptosis in gastric cancer cells both in vitro and in vivo. Biochem Biophys Res Commun. 2012; 417:864-868.

85. Williams S, Tucci MA, Benghuzzi HA. The effect of combination treatments of epigallocatechin-3-gallate, thymoquinone, and 5-Fluorouracil on fadu nasopharyngeal carcinoma cells. Biomed Sci Instrum. 2014; 50:361-366.

86. Harpole JL, Tucci M, Benghuzzi H. Pathophysiological Effects of Thymoquinone and Epigallocatechin-3-Gallate on SK-OV-3 Ovarian Cancer Like Cell Line. Biomed Sci Instrum. 2015; 51:31-39.

87. Kensara OA, El-Shemi AG, Mohamed AM, Refaat B, Idris S, Ahmad J. Thymoquinone subdues tumor growth and potentiates the chemopreventive effect of 5-fluorouracil on the early stages of colorectal carcinogenesis in rats. Drug Des Devel Ther. 2016; 10:2239-2253.

88. Effenberger-Neidnicht K, Schobert R. Combinatorial effects of thymoquinone on the anti-cancer activity of doxorubicin. Cancer Chemother Pharmacol. 2011; 67:867-874.

89. Arafa el-SA, Zhu Q, Shah ZI, Wani G, Barakat BM, Racoma I, El-Mahdy MA, Wani AA. Thymoquinone up-regulates PTEN expression and induces apoptosis in doxorubicin-resistant human breast cancer cells. Mutat Res. 2011; 706:28-35.

90. Jafri SH, Glass J, Shi R, Zhang S, Prince M, KleinerHancock H. Thymoquinone and cisplatin as a therapeutic combination in lung cancer: In vitro and in vivo. J Exp Clin Cancer Res. 2010; 29:87.

91. Ng WK, Yazan LS, Ismail M. Thymoquinone from Nigella sativa was more potent than cisplatin in eliminating of $\mathrm{SiHa}$ cells via apoptosis with down-regulation of Bcl-2 protein. Toxicol In Vitro. 2011; 25:1392-1398.

92. Wilson AJ, Saskowski J, Barham W, Yull F, Khabele D. Thymoquinone enhances cisplatin-response through direct tumor effects in a syngeneic mouse model of ovarian cancer. J Ovarian Res. 2015; 8:46.

93. Siveen KS, Mustafa N, Li F, Kannaiyan R, Ahn KS, Kumar AP, Chng WJ, Sethi G. Thymoquinone overcomes chemoresistance and enhances the anticancer effects of bortezomib through abrogation of $\mathrm{NF}-\kappa \mathrm{B}$ regulated gene products in multiple myeloma xenograft mouse model. Oncotarget. 2014; 5:634-648. doi: 10.18632/oncotarget.1596.
94. Dirican A, Atmaca H, Bozkurt E, Erten C, Karaca B, Uslu R. Novel combination of docetaxel and thymoquinone induces synergistic cytotoxicity and apoptosis in DU-145 human prostate cancer cells by modulating PI3K-AKT pathway. Clin Transl Oncol. 2015; 17:145-151.

95. Mu GG, Zhang LL, Li HY, Liao Y, Yu HG. Thymoquinone Pretreatment Overcomes the Insensitivity and Potentiates the Antitumor Effect of Gemcitabine Through Abrogation of Notch1, PI3K/Akt/mTOR Regulated Signaling Pathways in Pancreatic Cancer. Dig Dis Sci. 2015; 60:1067-1080.

96. Kortüm B, Campregher C, Lang M, Khare V, Pinter M, Evstatiev R, Schmid G, Mittlböck M, Scharl T, Kucherlapati MH, Edelmann W, Gasche C. Mesalazine and thymoquinone attenuate intestinal tumour development in Msh2(loxP/loxP) Villin-Cre mice. Gut. 2015; 64:1905-1912.

97. Dirican A, Erten C, Atmaca H, Bozkurt E, Kucukzeybek Y, Varol U, Oktay Tarhan M, Karaca B, Uslu R. Enhanced cytotoxicity and apoptosis by thymoquinone in combination with zoledronic acid in hormone- and drug-resistant prostate cancer cell lines. J BUON. 2014; 19:1055-1061.

98. Ganji-Harsini S, Khazaei M, Rashidi Z, Ghanbari A. Thymoquinone Could Increase The Efficacy of Tamoxifen Induced Apoptosis in Human Breast Cancer Cells: An In Vitro Study. Cell J. 2016; 18:245-254.

99. Pazhouhi M, Sariri R, Rabzia A, Khazaei M. Thymoquinone synergistically potentiates temozolomide cytotoxicity through the inhibition of autophagy in U87MG cell line. Iran J Basic Med Sci. 2016; 19:890-898.

100. Mohamed AM, Refaat BA, El-Shemi AG, Kensara OA, Ahmad J, Idris S. Thymoquinone potentiates chemoprotective effect of Vitamin D3 against colon cancer: a pre-clinical finding. Am J Transl Res. 2017; 9:774-790.

101. Velho-Pereira R, Kumar A, Pandey BN, Jagtap AG, Mishra KP. Radiosensitization in human breast carcinoma cells by thymoquinone: role of cell cycle and apoptosis. Cell Biol Int. 2011; 35:1025-1029.

102. Imani S, Wei C, Cheng J, Khan MA, Fu S, Yang L, Tania M, Zhang X, Xiao X, Zhang X, Fu J. MicroRNA-34a targets epithelial to mesenchymal transition-inducing transcription factors (EMT-TFs) and inhibits breast cancer cell migration and invasion. Oncotarget. 2017; 8:21362-21379. doi: 10.18632/oncotarget.15214. 